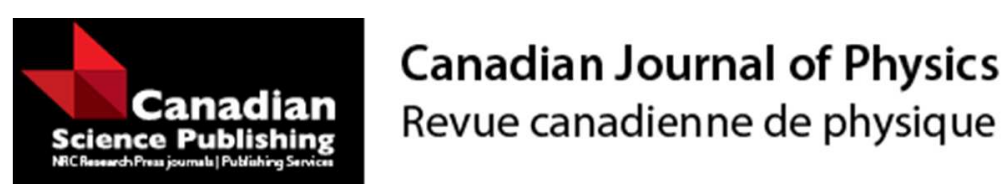

\title{
Students' opinions on the educational value of physics laboratories: a cross-sectional survey
}

\begin{tabular}{|r|l|}
\hline Journal: & Canadian Journal of Physics \\
\hline Manuscript ID & cjp-2016-0358.R1 \\
\hline Manuscript Type: & Article \\
\hline Date Submitted by the Author: & 23-Jun-2016 \\
\hline Complete List of Authors: & $\begin{array}{l}\text { Leung, Anthony; York University, } \\
\text { Terrana, Alexandra ; York University, Physics and Astronomy; Perimeter } \\
\text { Institute for Theoretical Physics } \\
\text { Jerzak, Stanislaw; York University, Physics and Astronomy }\end{array}$ \\
\hline Keyword: & $\begin{array}{l}\text { physics education research, physics laboratory, university students, } \\
\text { collaborative learning, cross-sectional survey }\end{array}$ \\
\hline
\end{tabular}




\title{
Students' opinions on the educational value of physics laboratories: a cross-sectional survey
}

\author{
Anthony C. K. Leung, ${ }^{1}$ Alexandra Terrana, ${ }^{1,2}$ and Stanislaw Jerzak ${ }^{1, *}$ \\ ${ }^{1}$ Department of Physics and Astronomy, \\ York University, Toronto, Ontario, M3J 1P3, Canada \\ ${ }^{2}$ Perimeter Institute for Theoretical Physics, \\ Waterloo, Ontario, N2J 2W9, Canada
}

(Dated: July 12, 2016)

\begin{abstract}
Physics laboratories are currently under pressure to reform due to the growing evidence that students are not learning effectively in the lab. Unfortunately, there is no consensus on what the most important goals for the laboratories should be or how to implement them. With the overall value and purpose of physics laboratories in question, we have set out to determine the opinions of the students themselves. How valuable do students perceive physics labs to be, what skills do they find useful in the lab, and what kinds of lab technologies do they prefer? We accomplished this through a nationwide cross-sectional online survey of physics majors, at both undergraduate and graduate levels, receiving responses from a total of 445 students from 20 post-secondary Canadian institutions. The present survey shows that students recognize the usefulness of many laboratory aspects. However, despite the best intentions of educators, there are a few components that students do not find as useful.
\end{abstract}

PACS numbers: 01.40.Fk, 01.30.Rr

Keywords: physics education research, physics laboratory, cross-sectional survey, collaborative learning, university students

\footnotetext{
* jerzak@yorku.ca
} 


\section{INTRODUCTION}

The laboratory is an integral part of the physics curriculum at almost all universities, with hundreds of thousands of students partaking in laboratory activities around the world every year. Labs are generally strongly valued within the physics community, stemming from the idea that they can motivate and enthuse students, as well as teach them an assortment of skills and concepts. Despite their potential value, along with huge amounts of required space, equipment, and human resources, the effectiveness of learning in laboratories has been questioned [1-5]. As a result, many physics departments have made attempts to improve their instructional approaches in the laboratory in a variety of ways, particularly focusing on learning by inquiry. There is an enormous breadth of lab activities, teaching strategies, and educational technologies, including computer-based and even virtual labs [6-10]. Therefore, it is not surprising that the laboratory took centre stage as the theme of the 2015 Physics Education Research Conference [11].

The variety of instructional approaches reflects the diversity of learning outcomes for physics laboratories [12]. Most often cited goals include development of critical thinking skills, learning how to use lab equipment, improving understanding of concepts learned in lectures, perform experimental data and uncertainty analyses, fostering students interest in physics, and development of collaboration skills. Similar lists of goals have been outlined by Wieman [3] and by the American Association of Physics Teachers [13]. Faced with these diverse learning expectations, educators passionately debate the types of laboratory experiments that are best suited to fulfill the wide range of objectives, and there is a definite lack of consensus towards the serious purpose of the laboratory. For instance, recent research shows that labs do not improve conceptual understanding of physics, as measured by exam results for two first-year courses, one with and one without a lab component [2]. From this result one could argue that the goals should be more skills focused.

There is also increasing usage of computer-based lab technologies. For example, in microcomputer-based labs (MBL), or simply known as "computer-based labs", students use a computer and associated probes (e.g., temperature, motion, sound, etc.) to collect, visualize, and analyze data obtained during the experiment. These tools are sometimes referred to as "inquiry empowering technologies" [14], since the automated data analysis process allows more time for (and possibly even enhances) conceptual and critical thinking. 
For these reasons it has been argued that MBLs offer an improved lab experience involving techniques that reflect actual methods used in research [15-18].

Another example is virtual physics labs, in which a simulated physics experiment is done entirely on a computer. With increasing advances in technology and the quality of simulations, the convenience and the cost effectiveness of virtual labs have made them more popular as an option for distance and online education [19]. The use of this technology can already be seen in a flipped classroom approach at the University of British Columbia [20] where first-year physics labs take place online. Moreover, a study by Finkelstein et al. [9] showed that substituting a computer simulation for real laboratory equipment led to better conceptual and practical understanding. In another study, Darrah et al. [21] found that virtual labs can be just as effective as traditional labs in terms of learning outcomes. While there is clearly a huge potential gain from technological advancements in physics labs, it is imperative to understand how to implement them to maximize student learning.

Efforts have been put forth to elucidate what and how students learn in the physics laboratory [14, 22-24], but designing this type of research is challenging, as there are many confounding variables that are difficult to avoid. Ideally, any such research endeavour should be a properly designed experiment with large study and control groups, covering multiple institutions and levels, supplemented by qualitative studies that include interviews and observations. Although such research is our future goal, we present here our immediate first step: a cross-sectional survey covering all levels of undergraduate and graduate physics, astronomy, biophysics and other physics-related disciplines. The cross-sectional design of the study highlights students' changing perspectives regarding learning in the physics lab. For instance, should the goals for first year labs be different than higher level labs, and if so, in what ways? Our survey reveals a number of issues that should help in designing a more extensive study regarding learning effectiveness in the laboratory.

The methods of the present study are described in Sec. II. Survey results are given and discussed in Sec. III. Finally, we provide our concluding remarks and outlook in Sec. IV.

\section{METHODOLOGY}

The present study consists of an internet-based survey created through Google Forms. The population of this study is university physics students in Canada. We contacted the https://mc06.manusç̧iptcentral.com/cjp-pubs 
physics departments of over 25 major post-secondary institutions across the nation, requesting that the link to our survey be forwarded to undergraduate physics majors at all levels and graduate students in physics (or astronomy, biophysics, or other related streams). The cross-sectional data was collected from March to April 2016. To ensure a good response rate, e-mail reminders were sent in the beginning of April.

In total, 445 responses from 20 institutions were received. The complete breakdown of the number of respondents is shown in Table I. The proportion of respondents coming from each institution varied in the percentage of students responding, ranging from $1 \%$ coming from the University of Prince Edward Island to 14\% from the University of Toronto. Although the latter institution is the largest in our sample, responses from other institutions are comparable in size, such as York University (12\%), Carleton University (10\%) and the University of Victoria (10\%).

The survey required students to identify themselves by academic (class) level and average grade. For class levels, the survey asked, "What level of physics courses are you currently taking?" with five options ranging from four undergraduate (UG) levels and the graduate level (GL). The grades were self-reported by the students, as the survey stated, "Identify the percent range that best describes your average grade," and four options were given: (i) below $70 \%$ (C+ and below), (ii) between 70 to $79 \%$ (B- to $\mathrm{B}+$ ), (iii) 80 to $89 \%$ (A- to A), and (iv) above $90 \%(\mathrm{~A}+)$. Table II shows the sample population distribution with respect to both class and grade level, demonstrating a fairly even distribution across all levels with the exception from the "below 70\%" and GL groups.

Survey participation was entirely voluntary and anonymous for all students. To encourage students to participate, 10 electronic gift cards of equal monetary value were offered to randomly selected participants. When students click the link to the survey, they are immediately shown the ethics approval obtained from the Office of Research Ethics at York University. The preamble stated, "This research has received ethics review and approval by the Human Participants Review Sub-Committee, York University's Ethics Review Board and conforms to the standards of the Canadian Tri-Council Research Ethics guidelines." The instruction stated, "Clicking on the 'agree' button below indicates that you voluntarily agree to participate the survey."

To avoid the issue of missing cases, students are required to respond to all questions in the survey. Most of the survey questions are centred on a different theme than the one presented 
in this report. The central theme of the survey deals with students' usage of online resources in their physics education, such as online lectures and course material. The results regarding this topic has been deferred in a separate report. In a subsection of the survey, three crucial questions were also asked regarding physics laboratories, and the results of these questions form the basis of this work. The three questions, which we label as Q.1, Q.2 and Q.3 for the purpose of this report, were the following:

Q.1 "How valuable on a scale of 1 (no value) to 5 (extreme value) were your physics laboratory experiences throughout your physics education?"

Q.2 "From your experience, what were the most useful aspects of physics labs?" Seven options were given and are explained in the next section.

Q.3 "What is your preference regarding the type of laboratory component?" Three options were given and briefly described in the survey: (i) "Traditional lab by means of using physical equipment only (e.g., digital multimeter, oscilloscopes)", (ii) "Virtual lab with online simulations", and (iii) "Microcomputer-based lab (i.e., using a computer to collect and analyze data)." As the descriptions implies, the focus of this question is to gauge students' preference on the interaction with equipment/instruments, and not on the instructional method (e.g., conceptual-based discovery style) since this can differ across institutions.

Statistical analyses were performed on the survey responses to determine whether certain variables are related. The main objective of this work is to compare survey response distributions across class levels. While comparisons were also performed on survey responses grouped by grade levels, they were found to be insignificant, and thus, they are not highlighted in this report. To carry out the analyses, the appropriate statistical test was applied to each question where the standard $p$-value is obtained. We follow the standard convention where if the $p$-value is less than the significance level $\alpha$, which was assigned to 0.05 in this study, then the test indicates a significant difference. Moreover, the effect size of each test is also provided since the $p$-value is insufficient to make an appropriate interpretation [2527]. All statistical tests and graphs were produced using the Statistical Package for Social Sciences (SPSS). 
The analysis of variance (ANOVA) was performed on the responses for Q.1 because results of more than two independent groups are being compared. Since there are a number of ways to calculate the effect size for an ANOVA test, the present analysis reports the omegasquared $\left(\omega^{2}\right)$ effect size as it is the least biased [27]. Even though the dependent variable for this question is ordinal, parametric statistics have been shown to be quite robust as explained in Ref. [28] (and references therein). If the ANOVA indicates significant difference among the response distributions, then pairwise $t$-tests are carried out in order to identify where the difference(s) occur. Its corresponding effect size is the Cohen's $d$ [27].

For Q.2, the Cochran's $Q$ test [29] was performed on the responses since students can select multiple options and these options are treated as dichotomous variables. This test indicates whether heterogeneity (or consistency) of responses is present among the data set. Since this test does not indicate where the difference(s) lie among the group of items, post hoc McNemar's pairwise tests [30] are to be carried out. Moreover, since the effect size for the Cochran's $Q$ test can be problematic [31], for simplicity, we restrict the effect size calculation on the McNemar's chi-squared $\left(\chi^{2}\right)$ test statistic by using Cramer's $V$ [32].

Finally, the Pearson's $\chi^{2}$ independence test was performed on the Q.3 responses since the variables are categorical (nominal). Note that Pearson's $\chi^{2}$ is different from McNemar's $\chi^{2}$ since the latter tests for heterogeneity of responses. For the effect size, the unbiased Cramer's $V$ [33] was computed. Although the unbiased Cramer's $V$ could be used for the McNemar's test, SPSS does not generate the data needed to carry out such calculation.

In this report, all computed effect sizes are classified according to Ref. [25]. We made note that certain labels in SPSS can be misleading and that they have been properly used in this study for effect size calculations [34]. Results of all statistics are reported using the American Psychology Association (APA) style. The results and interpretation of our analysis are presented in the following section.

\section{RESULTS AND DISCUSSION}

\section{A. Overall physics lab experience}

We present the results of each of the three lab-related survey questions. Beginning with Q.1, Figure 1 shows the relative frequency plot of students responses regarding the overall 
value of their physics lab learning experiences. Each value level in the cluster plot shows the relative frequency of each class level. By considering the entire sample population, the plot shows that a large proportion of students find that their overall learning experiences in physics laboratories hold much value or more $(M=3.6, S D=1.11, N=445)$. Specifically, about $58 \%$ of respondents rated physics labs with much value or more, $26 \%$ with average value, and the remaining respondents (16\%) with limited or no value. In other words, the survey results show that students' overall value of the physics lab is positive.

In more detail, Table III shows the mean value for each class level. It is of interest to see whether there is any significant differences of the perceived value of physics labs between class levels. We hypothesized that a large proportion of GL students would have a greater value towards physics labs compared to UG-1 students simply because GL students would have taken more advanced courses, and had a chance to build on and appreciate the valuable skills learned in the lab. However, the survey did not demonstrate any significant difference in the mean value level of physics labs across all classes; $F(4,440)=1.16, p=0.33, \omega^{2}<0.001$. Considering the small effect size, this suggests that students' perceptions of the overall value of physics labs are not significantly altered as they progress through their physics education career.

\section{B. Useful physics lab aspects}

Next in Q.2, students were asked to select the learning aspect(s) of physics labs that they found useful. Students were allowed to select more than one option for this question, but their selections were not ranked. The items listed in the survey were based on the most common learning outcomes and expectations in a typical science laboratory curriculum. We offered the following aspects in the survey:

- Group collaboration.

- Learning to gather and analyze data.

- Learning to perform uncertainty analysis.

- Getting hands-on experience with lab equipment.

- Enhancing critical thinking skills. 
- Theory application.

The survey also allowed students to report other useful aspects under the 'Other' category. If students do not find any aspects useful, an option for 'None' was available as well.

Responses regarding the useful aspects of physics labs are shown in Fig. 2. Some labels in the vertical axis were shortened for presentation purposes but follows in the order of the list mentioned above. Table IV shows the detailed breakdown of responses, including the 'None' and 'Other' categories which are absent in Fig. 2. Note that the percentages appearing in the figure are different than in the table. The figure shows the proportion relative to the total number of responses within a lab aspect while the table shows the proportion relative to its respective class group. Considering the entire sample population, Fig. 2 shows that the response rate across the different aspects is not evenly distributed. By the Cochran's $Q$ test on this data set, the survey responses indicates a systematic difference among the items that students find useful about the physics labs, $p<0.001$.

By inspection of Fig. 2 and Table IV, the top three choices by students were: data analysis, uncertainty analysis, and hands-on experience. The item that has the fewest responses is group collaboration. This pattern of selection can be seen at every class level. Furthermore, McNemar post hoc tests were conducted on various pairs of items to verify the difference in proportion of positive responses. For simplicity, the entire sample population was considered for the McNemar's tests. From one paired test, the proportion of positive responses between data analysis and uncertainty analysis are virtually the same; $p=1.00$ (two-sided), $V<$ 0.001 . However, there is a large difference in the proportion of positive responses between data analysis and group collaboration; $p<0.001$ (two-sided), $V=0.47$. Similarly, there is a significant difference in the proportion of positive responses between uncertainty analysis and group collaboration; $p<0.001$ (two-sided), $V=0.46$.

There are some response distributions to comment on. In the uncertainty analysis category, the proportion of positive responses increases with respect to class level (see Fig. 2 and Table IV). However, no association was found between a student's attitude towards uncertainty analysis as a useful skill and their class level; $\chi^{2}(4, N=445)=5.78, p=0.22$, $V=0.06$.

Under the lab equipment category, there is a general decrease in the proportion of positive responses as class level increases. The results do indicate an association between class level and attitude towards hands-on experiences with lab equipment, but this association is weak; 
$\chi^{2}(4, N=445)=15.54, p=0.004, V=0.16$. Regardless, we speculate that this may be due to aging equipment used in advanced upper-year lab courses. Students have no choice but to use this aging equipment, which can lead to frustration when it fails to function properly. Another possible scenario is that, coming from high schools with limited resources, UG-1 students have a high sense of excitement being introduced to sophisticated lab equipment (i.e., a sense of novelty). However, since physics labs are more frequent at the post-secondary level, this sense of excitement might diminish as students advance in their education.

Group collaboration was the aspect with the fewest responses, selected by $38 \%$ of students in the sample population. Peer collaboration has shown to enhance conceptual learning and problem solving in the physics classroom [35-37], as well as improve students' attitudes and communication skills [38-40]. For this reason, pair or group work is a common practice for introductory labs. Being able to work as a team is also an invaluable skill from the perspective of employers.

From the survey results, more than half of the sample population did not select group work as a useful aspect. Based on typical complaints from students, such as dealing with slacking group members (also known as "free-riders") [38, 41], having disagreements, and the unfairness of sharing a grade, they probably think that the drawbacks outweigh the value. Another factor that can also diminish the benefits of group work is poor use of grouping techniques. For example, grouping students by ability can improve academic performance for weaker students [42-44], but as Randall [45] pointed out, this type of cooperative learning may place a burden on stronger students. The present survey results indicate that academic ability is associated with perceptions about the usefulness of group work in labs; $\chi^{2}(3, N=$ $445)=9.90, p=0.019, V=0.15$. However, since the effect size is small, the difference is not large. A recent work by Harlow et al. [46] also showed that students' satisfaction can be different if students are grouped differently by strength (mixed or sorted), but the difference in satisfaction was found to be small.

The aspect of enhancing critical thinking skills in the physics lab resulted in the second fewest number of responses in our survey. Specifically, about $50 \%$ of the sample population found this aspect useful. This could be explained by the fact that many physics labs may still be using the expository cook-book style where students mainly follow a series of instructions to collect data in experiments [47]. Not surprisingly, this style of teaching labs has often been criticized to not meet inquiry expectations [48] such as ones set by the National Science 
Education Standards [49].

In general, we see that students that found physics labs to be of average value or more in Q.1 selected three or more aspects in Q.2. In contrast, students that viewed physics labs to be of limited value or less in Q.1 selected no more than three items. Perhaps an encouraging observation seen from the responses in Table IV is that only 5 out of 445 respondents selected 'None'. In the 'Other' category, students input different aspects of the lab that they found valuable, some of the notable responses being,

- Equipment/apparatus debugging,

- Narrowing the field of interest within the Physics discipline,

- Further experimentation,

- Learning how to write formal lab reports,

- Learning the process to verify hypotheses (i.e., the scientific method).

\section{Traditional versus computer-based physics labs}

Finally, in Q.3, students were asked about the setup of the physics labs that they prefer. The choices given for this question were: traditional lab, virtual lab, and microcomputerbased lab. We also included an option for 'No preference/opinion'. Students can only select one answer for this question. Figure 3 shows the results for this question and Table V shows the numerical breakdown of these responses.

We hypothesized that students in upper UG years and GL would favour traditional labs over virtual labs since these students would have gained a better understanding and appreciation for various advanced laboratory skills and techniques. However, by comparing the response distribution across class levels (Table V), we see that they are similar to one another. Hence, our survey results did not demonstrate any association between a student's class level and their preferred lab setup; $\chi^{2}(12, N=445)=10.97, p=0.53, V=0.09$.

We hypothesized that MBL would be a more popular choice than traditional labs due to the advanced instruments involved in the former for efficient data collection. However, present results show that the traditional lab is the most popular choice with a relatively large disparity to MBL (Fig. 3). We can relate this result to responses from Q.2 where students 
seem to value the data and uncertainty analysis aspects of labs (see Fig. 2), appreciating the fact that these skills cannot be fully developed in lectures. The MBL approach makes some of the data collection automated, meaning that students would potentially miss out on learning these fundamentals. This does not suggest that MBL technologies should not be used in physics labs, but that students might not want all labs to have computerized data collection.

Virtual lab had the fewest number of selections. The large disparity between traditional and virtual labs could be due to the fact that the latter is, at least in physics education, not a common teaching practice [50]. As a result, it is possible that some students cannot make a good comparison between the two styles of labs. However, we can partially understand this disparity by referring to Fig. 2 where students really value the hands-on aspects of traditional labs, such as working with lab equipment. In the study by Bhargava et al. [19] where the efficacy of a web-based virtual torsion laboratory was investigated, results of a survey showed that most students (65\%) would prefer doing physical labs than virtual ones (19\%). Some of the most cited reasons for this include: enjoyment of hands-on experience, being able to observe the physical experiment, and having a teaching assistant present to answer questions [19]. This type of response can be seen in non-physics majors as well [51]. It is clear that the features of traditional labs are difficult to produce or replicate in a virtual environment.

\section{CONCLUSIONS AND OUTLOOK}

Physics laboratories can be an immensely important component of physics education at the university level. With large amounts of resources required to develop and maintain physics labs, finding methods to optimize student learning in the lab environment is a growing field of research. There is indeed a desire to be more innovative in designing the lab curriculum, both in the instructional approach, as well as in the use of educational technologies. More research is desperately needed regarding what and how students learn in the lab, and thus how to proceed with improvements in lab design.

Based on the present nationwide cross-sectional online survey of physics majors, students believe that their own laboratory experiences have been valuable. When asked to select lab aspects that students find useful, the most popular choice was getting hands-on experience 
with equipment, followed closely by learning uncertainty and data analysis skills. We are thus led to believe that students really enjoy the physical aspect of working with lab equipment, and appreciate the lab's ability to teach valuable data and uncertainty analysis methods. This is consistent with their responses in regards to experiment interaction, in which students showed a strong preference for physical equipment in traditional labs as opposed to virtual labs. Concerning all questions, the survey did not reveal any significant association between the students' perceptions of physics labs and their class level.

In the present survey, group collaboration, engaging in critical thinking, and applying theoretical concepts were the least selected aspects of physics laboratories. This is somewhat discouraging as these are some of the fundamental desired learning outcomes of labs. Encouraging team work that is constructive and valuable for all students should be one of the priorities in physics laboratories. Additionally, current efforts to improve physics labs are focusing on enhancing critical thinking using an inquiry based approach [14, 52]. Designing labs that reflect the scientific process could engage students in developing their inquiry skills and strengthening their perceptions about scientific research. Nevertheless, the other important learning goals of labs should not be diminished.

The list of desired learning goals for physics laboratories is undoubtedly staggering, and the importance of each goal can be fully justified. Referring back to Fig. 2, although the relative frequencies vary in each category, it is evident that students generally do recognize all of these learning aspects to a large degree. This is overwhelming for instructors trying to create a lab curriculum that can successfully implement every aspect. A single lab experiment cannot reasonably accomplish all goals. Rather than trying to incorporate all of these aspects into a single lab, it might be more beneficial to design labs that are more specialized, with each experiment focusing on a smaller subset of skills. For example, some labs can emphasize data collection and graphing analysis, others can focus on uncertainties and model testing, and so forth. Throughout a student's entire physics education, performing many experiments, they should have an opportunity to develop all of these skills.

Lastly, let us remark on the potential impact of new lab technologies. Concerning virtual labs, the low positive responses could be related to the high value placed on the hands-on aspect of labs from students; a result that was also observed by Bhargava et al. [19]. However, this could just be an issue of students' not recognizing the actual learning outcomes of virtual labs $[7,9]$. Living in a technology-centred era, virtual lab simulations are improving 
in quality and educational potential, so it is conceivable that they could play a very useful role. For example, they can help students visualize non-intuitive concepts in quantum mechanics [53]. Virtual labs can also be a great substitute when there is no available equipment. When physical equipment already exists, it is perhaps more beneficial to explore how these simulations can provide an additional effective learning experience. For example, the hybrid use of physical equipment, simulations and MBL instruments are crucial to the physics practicals at the University of Toronto to enrich collaborative learning [54]. Other institutions implementing similar innovative techniques include the University of Calgary [55], North Carolina State University with their Student-Centered Active Learning Environment with Upside-down Pedagogies [56] and Massachusetts Institute of Technology implementing this format in their Technology Enabled Active Learning style [57]. The intersections of laboratory activities, new technologies, and how students learn require special attention by physics education researchers moving forward.

\section{ACKNOWLEDGEMENTS}

The survey study presented in this report was made possible through the help from a number of physics departments across Canada that have agreed to participate in this research. Without their assistance, collection of this data set would not have been successful. All participants of this survey study are also gratefully acknowledged by the authors. The authors are also grateful for discussions with Dr. Banafsheh Hashemi Pour during the initial stages of the project.

[1] M. Robinson, American Journal of Physics 47, 859 (1979).

[2] C. Wieman and N. G. Holmes, Am. J. Phys. 83, 972 (2015).

[3] C. Wieman, Phys. Teach. 53, 349 (2015).

[4] R. T. White, Int. J. Sci. Educ. 18, 761 (1996).

[5] A. Hofstein and V. N. Lunetta, Rev. Educ. Res. 52, 201 (1982).

[6] D. R. Sokoloff, P. W. Laws, and R. K. Thornton, Eur. J. Phys. 28, S83 (2007).

[7] C. E. Wieman, W. K. Adams, and K. K. Perkins, Science 322, 682 (2008).

[8] R. Trumper, Sci. Educ. 12, 645 (2003). 
[9] N. D. Finkelstein, W. K. Adams, C. J. Keller, P. B. Kohl, K. K. Perkins, N. S. Podolefsky, S. Reid, and R. LeMaster, Phys. Rev. Spec. Top. - Phys. Educ. Res. 1, 010103 (2005).

[10] T. Karakasidis, in 2013 IEEE Glob. Eng. Educ. Conf. (IEEE, 2013) pp. 798-807.

[11] A. D. Churukian, D. L. Jones, and L. Ding, eds., 2015 PERC Proceedings (Physics Education Research Conference, 2015) (Available online: http://www.compadre.org/per/perc/ conference. $\operatorname{cfm}$ ?Y=2015).

[12] A. A. of Physics Teachers, Am. J. Phys. 66, 483 (1998).

[13] AAPT Recommendations for the Undergraduate Physics Laboratory Curriculum, American Association of Physics Teachers, College Park, MD (2014), (Available online: http://www . aapt.org/Resources/upload/LabGuidlinesDocument_EBendorsed_nov10.pdf).

[14] A. Hofstein and V. N. Lunetta, Sci. Educ. 88, 28 (2004).

[15] B. Royuk and D. W. Brooks, J. Sci. Educ. Technol. 12, 317 (2003).

[16] E. F. Redish, Am. J. Phys. 65, 45 (1997).

[17] D. W. Russell, K. B. Lucas, and C. J. McRobbie, Research in Science Education 33, 217 (2003).

[18] R. K. Thornton, Physics Education 22, 230 (1987).

[19] P. Bhargava, J. Antonakakis, C. Cunningham, and A. T. Zehnder, Computer Applications in Engineering Education 14, 1 (2006).

[20] Flexible Learning - Flipped Classroom, The University of British Columbia, accessed June 14, 2016, http://flexible-learning2015.sites.olt.ubc.ca/files/2015/ 03/flipped-classroom.pdf.

[21] M. Darrah, R. Humbert, J. Finstein, M. Simon, and J. Hopkins, Journal of Science Education and Technology 23, 803 (2014).

[22] A. Richardson, M. Sharma, and J. Khachan, CAL-laborate Int. , 20 (2008).

[23] B. M. Zwickl, T. Hirokawa, N. Finkelstein, and H. J. Lewandowski, AIP Conf. Proc. , 381 (2014), arXiv:1307.5760v1.

[24] B. M. Zwickl, T. Hirokawa, N. Finkelstein, and H. J. Lewandowski, Phys. Rev. Spec. Top. Phys. Educ. Res. 10, 010120 (2014).

[25] J. W. Kotrlik, H. A. Williams, and M. K. Jabor, Journal of Agricultural Education 52, 132 (2011). 
[26] C. O. Fritz, P. E. Morris, and J. J. Richler, Journal of Experimental Psychology: General 141, 2 (2012).

[27] D. Lakens, Frontiers in Psychology 4, 863 (2013).

[28] G. Norman, Advances in Health Sciences Education 15, 625 (2010).

[29] W. G. Cochran, Biometrika 37, 256 (1950).

[30] Q. McNemar, Psychometrika 12, 153 (1947).

[31] K. J. Berry, J. E. Johnston, and P. W. Mielke Jr, Perceptual and Motor Skills 104, 1236 (2007).

[32] M. Tomczak and E. Tomczak, Trends in Sport Sciences 21 (2014).

[33] W. Bergsma, Journal of the Korean Statistical Society 42, 323 (2013).

[34] T. R. Levine and C. R. Hullett, Human Communication Research 28, 612 (2002).

[35] R. R. Hake, American Journal of Physics 66, 64 (1998).

[36] C. H. Crouch and E. Mazur, Am. J. Phys. 69, 970 (2001).

[37] S. Freeman, S. L. Eddy, M. McDonough, M. K. Smith, N. Okoroafor, H. Jordt, and M. P. Wenderoth, Proceedings of the National Academy of Sciences 111, 8410 (2014).

[38] D. Boud, R. Cohen, and J. Sampson, Assessment \& Evaluation in Higher Education 24, 413 (1999).

[39] A. C. K. Leung, B. Hashemi Pour, D. Reynolds, and S. Jerzak, Assess. Eval. High. Educ. 2938, 1 (2015).

[40] A. Cancela, R. Maceiras, A. Sánchez, M. Izquierdo, and S. Urréjola, European Journal of Engineering Education 41, 23 (2016).

[41] A. M. Abernethy and W. L. Lett, Mark. Educ. Rev. 15, 47 (2005).

[42] E. A. Hanushek, J. F. Kain, J. M. Markman, and S. G. Rivkin, J. Appl. Econ. 18, 527 (2003).

[43] E. A. Day, W. Arthur, S. T. Bell, B. D. Edwards, W. Bennett, J. L. Mendoza, and T. C. Tubré, Intelligence 33, 39 (2005).

[44] G. Braught, J. MacCormick, and T. Wahls, in Proceedings of the 41st ACM technical symposium on Computer science education (ACM, 2010) pp. 249-253.

[45] V. Randall, Education Digest 65, 29 (1999).

[46] J. J. B. Harlow, D. M. Harrison, and A. Meyertholen, Phys. Rev. Phys. Edu. Res. 12, 010138 (2016).

[47] D. S. Domin, J. Chem. Edu. 76, 543 (1999). 
[48] J. R. Brinson, Computers \& Education 87, 218 (2015).

[49] National Science Teacher Association (2013).

[50] G. Meisner, H. Hoffman, and M. Turner, Lat. Am. J. Phys. Educ. 2, 87 (2008).

[51] K. MacLeod, M. S. G. Razul, and J. Powell, Can. J. Phys. 93, 526 (2014).

[52] N. G. Holmes, C. E. Wieman, and D. A. Bonn, Proceedings of the National Academy of Science 112, 11199 (2015), 1508.04870 [physics.ed-ph].

[53] M. K. Pedersen, B. Skyum, R. Heck, R. Müller, M. Bason, A. Lieberoth, and J. F. Sherson, Phys. Rev. Phys. Educ. Res. 12, 013102 (2016).

[54] University of Toronto Physics Practicals, University of Toronto, Toronto, ON, accessed May 24, 2016, http://www. upscale.utoronto.ca/Practicals/.

[55] D. Ahrensmeir, J. Donev, R. Hicks, A. Louro, L. Sangalli, R. Stafford, and R. Thompson, Physics in Canada 65, 214 (2009).

[56] SCALE-UP: Student Centered Active Learning Environment with Upside-down Pedagogies, North Carolina State University, Raleigh, NC, accessed May 24, 2016, https://www.ncsu . edu/per/scaleup.html.

[57] TEAL - Technology Enabled Active Learning, Massachusetts Institute of Technology, Cambridge, MA, accessed May 24, 2016, http://web.mit.edu/edtech/casestudies/teal.html. 


\section{TABLES}

TABLE I. Sample population table showing the list of post-secondary institutions and the corresponding number of respondents.

\begin{tabular}{|c|c|c|}
\hline & Count & Percent \\
\hline Brock University & 15 & 3.4 \\
\hline Carleton University & 44 & 9.9 \\
\hline Dalhousie & 13 & 2.9 \\
\hline McGill & 9 & 2.0 \\
\hline Memorial University & 6 & 1.3 \\
\hline Perimeter Institute for Theoretical Physics & 4 & .9 \\
\hline Ryerson University & 5 & 1.1 \\
\hline Simon Fraser University & 26 & 5.8 \\
\hline University of Calgary & 29 & 6.5 \\
\hline University of Guelph & 25 & 5.6 \\
\hline University of Manitoba & 8 & 1.8 \\
\hline University of Ottawa & 18 & 4.0 \\
\hline University of Prince Edward Island & 5 & 1.1 \\
\hline University of Toronto (UofT) & 62 & 13.9 \\
\hline University of Victoria & 43 & 9.7 \\
\hline University of Waterloo & 35 & 7.9 \\
\hline University of Western Ontario & 15 & 3.4 \\
\hline UofT (Mississauga) & 14 & 3.1 \\
\hline UofT (Scarborough) & 15 & 3.4 \\
\hline York University & 54 & 12.1 \\
\hline Total & 445 & 100.0 \\
\hline
\end{tabular}


TABLE II. Sample population matrix.

\begin{tabular}{ll|rrrrrr}
\hline \hline & & \multicolumn{5}{c}{ Class level } & \\
\cline { 3 - 6 } & & UG-1 & UG-2 & UG-3 & UG-4 & GL & \\
\hline & below $70 \%$ & 25 & 11 & 7 & 5 & 0 & 48 \\
& $70-79 \%$ & 23 & 35 & 25 & 19 & 12 & 114 \\
Self-reported average grade & $80-89 \%$ & 27 & 28 & 33 & 32 & 59 & 179 \\
& $90 \%$ or above & 14 & 15 & 19 & 13 & 43 & 104 \\
\hline Total & & 89 & 89 & 84 & 69 & 114 & 445 \\
\hline \hline
\end{tabular}

TABLE III. Students' mean value level of their physics lab experience.

\begin{tabular}{lrrrr}
\hline \hline Class level & $N$ & Mean & Std. Dev. & Std. Error \\
\hline UG-1 & 89 & 3.40 & 1.17 & 0.12 \\
UG-2 & 89 & 3.74 & 1.09 & 0.12 \\
UG-3 & 84 & 3.65 & 0.98 & 0.11 \\
UG-4 & 69 & 3.65 & 0.98 & 0.12 \\
GL & 114 & 3.58 & 1.23 & 0.11 \\
\hline \hline
\end{tabular}


TABLE IV. Contingency table of physics lab aspects that university physics students found useful.

\begin{tabular}{|c|c|c|c|c|c|c|c|c|}
\hline & & & \multicolumn{5}{|c|}{ Class level } & \multirow{2}{*}{ Total } \\
\hline & & & UG-1 & UG-2 & UG-3 & UG-4 & GL & \\
\hline & Data collection \& & Count: & 56 & 69 & 62 & 52 & 82 & 321 \\
\hline & analysis & $\%$ within Class level & $63 \%$ & $76 \%$ & $74 \%$ & $75 \%$ & $72 \%$ & \\
\hline & & Count: & 56 & 65 & 60 & 50 & 89 & 320 \\
\hline & unces & $\%$ within Class level: & $63 \%$ & $73 \%$ & $71 \%$ & $73 \%$ & $78 \%$ & \\
\hline & Group & Count: & 42 & 38 & 29 & 21 & 44 & 174 \\
\hline & collaboration & $\%$ within Class level: & $47 \%$ & $43 \%$ & $35 \%$ & $30 \%$ & $39 \%$ & \\
\hline & Hands-on experience & Count: & 63 & 79 & 65 & 47 & 76 & 330 \\
\hline Lab & with equipment & \% within Class level: & $71 \%$ & $89 \%$ & $77 \%$ & $68 \%$ & $67 \%$ & \\
\hline aspects & Enhance critical & Count: & 39 & 46 & 40 & 32 & 62 & 219 \\
\hline & thinking & $\%$ within Class level: & $44 \%$ & $52 \%$ & $48 \%$ & $46 \%$ & $54 \%$ & \\
\hline & Apply theoretical & Count: & 58 & 65 & 56 & 45 & 70 & 294 \\
\hline & concepts & $\%$ within Class level: & $65 \%$ & $73 \%$ & $67 \%$ & $65 \%$ & $61 \%$ & \\
\hline & & Count: & 2 & 4 & 3 & 2 & 1 & 12 \\
\hline & & $\%$ within Class level: & $2 \%$ & $5 \%$ & $4 \%$ & $3 \%$ & $1 \%$ & \\
\hline & $\lambda$ & Count: & 1 & & 1 & 0 & 1 & 5 \\
\hline & 1VOHe & \% within Class level: & $1 \%$ & $2 \%$ & $1 \%$ & $0 \%$ & $1 \%$ & \\
\hline Total & & Count: & 317 & 368 & 316 & 249 & 425 & 1675 \\
\hline
\end{tabular}


TABLE V. Contingency table of university physics students' preferred format of physics labs.

\begin{tabular}{|c|c|c|c|c|c|c|c|c|}
\hline & & & \multicolumn{5}{|c|}{ Class level } & \multirow{2}{*}{ Total } \\
\hline & & & $\mathrm{UG}-1$ & UG-2 & UG-3 & $\mathrm{UG}-4$ & GL & \\
\hline \multirow{8}{*}{$\begin{array}{l}\text { Lab } \\
\text { format }\end{array}$} & \multirow{2}{*}{ Traditional } & Count & 44 & 51 & 41 & 38 & 59 & 233 \\
\hline & & $\%$ within Class level: & $49 \%$ & $57 \%$ & $49 \%$ & $55 \%$ & $52 \%$ & $52 \%$ \\
\hline & \multirow{2}{*}{ Virtual } & Count & 6 & 6 & 2 & 2 & 3 & 19 \\
\hline & & \% within Class level: & $7 \%$ & $7 \%$ & $2 \%$ & $3 \%$ & $3 \%$ & $4 \%$ \\
\hline & \multirow{2}{*}{ MBL } & Count & 18 & 17 & 20 & 20 & 27 & 102 \\
\hline & & \% within Class level: & $20 \%$ & $19 \%$ & $24 \%$ & $29 \%$ & $24 \%$ & $23 \%$ \\
\hline & \multirow{2}{*}{ No preference } & Count & 21 & 15 & 21 & 9 & 25 & 91 \\
\hline & & \% within Class level: & $24 \%$ & $17 \%$ & $25 \%$ & $13 \%$ & $22 \%$ & $20 \%$ \\
\hline \multirow[t]{2}{*}{ Total } & & Count & 89 & 89 & 84 & 69 & 114 & 445 \\
\hline & & $\%$ within Class level: & $100 \%$ & $100 \%$ & $100 \%$ & $100 \%$ & $100 \%$ & $100 \%$ \\
\hline
\end{tabular}




\section{LIST OF FIGURE CAPTIONS}

FIG. 1: Cluster bar plot of students' survey response on the value of physics laboratory learning and experiences. Each value level shows the relative frequency of mentions by class level.

FIG. 2: Cluster bar plot of students' survey responses on the useful aspect(s) of physics laboratory. Each bar shows the proportion of responses relative to the total number of responses within the lab aspect.

FIG. 3: Cluster bar plot of students' survey responses on the preferred format of the physics laboratory. Each aspect shows the relative frequency of respondents by class level. 


\section{FIGURES}

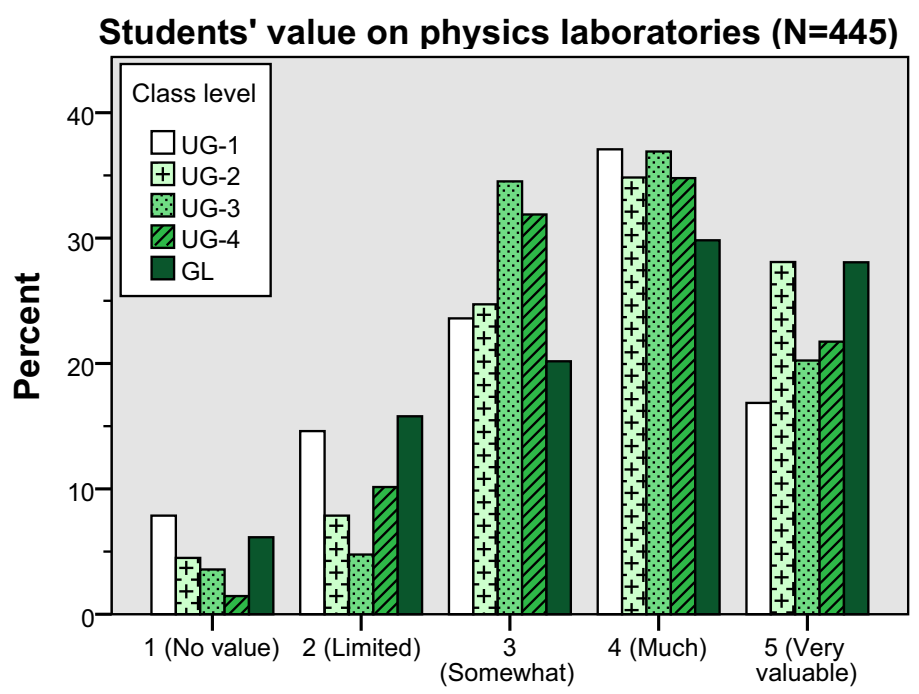

Value level

FIG. 1.

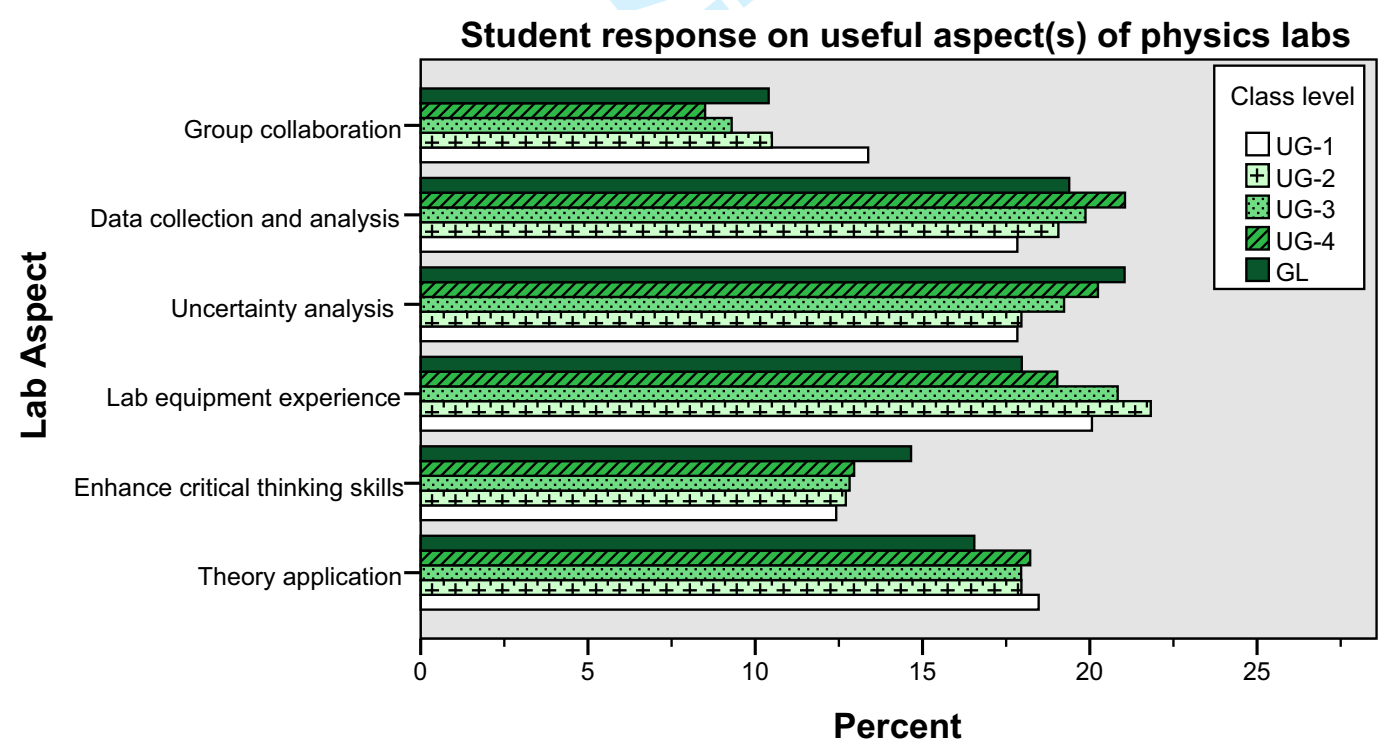

FIG. 2. 


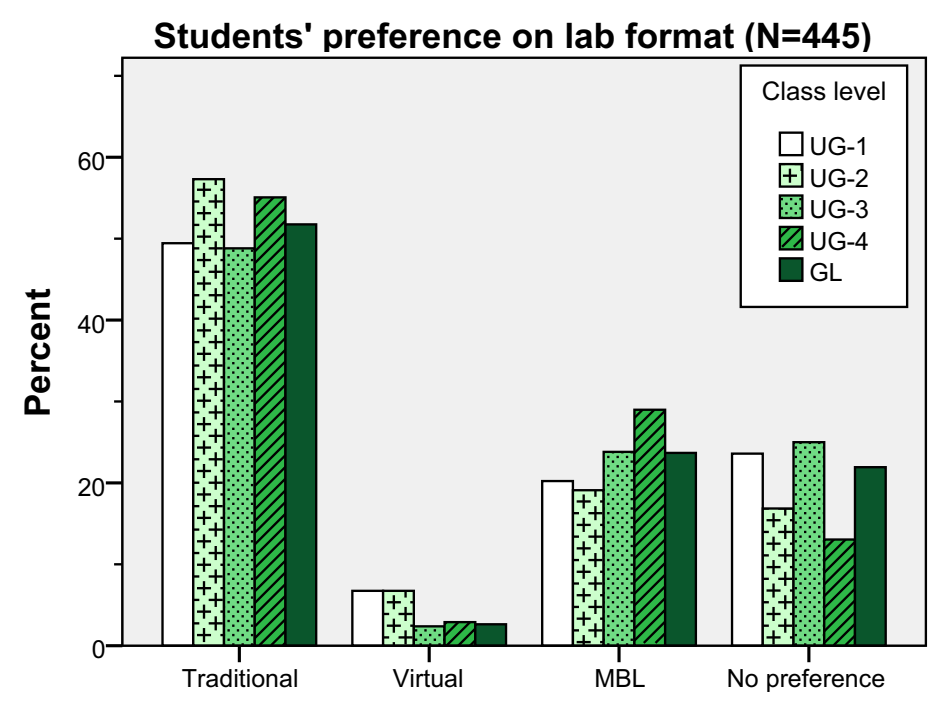

Physics lab format response

FIG. 3. 